\title{
Effect of Verbal and Visual Information on the Level of Anxiety among Dental Implant Patients
}

\author{
Mohammed Ghazi Sghaireen
}

\begin{abstract}
Aim: To compare the effect of visual information and verbal communication on the level of anxiety among patients undergoing dental implant (DI) therapy.

Materials and methods: A total of 270 patients who were undergoing DI treatment were recruited for the study. An equal number of patients $(n=90)$ were randomly allocated into three study groups which were formed on the basis of the mode of delivery. Subjects in group I received verbal information, whereas patients in group II were shown a video of surgery on manikins. Group III subjects were made to watch a video of surgery on a real patient. Before the surgery, anxiety levels were measured for all patients using the modified Corah dental anxiety scale (MDAS). Results: Questionnaires were filled by all patients and were later analyzed. The values of Cronbach's a and the behavioral involvement subscale were 0.89 and 0.91 , indicating hemogeneous sample. Patients of group I showed significantly reduced anxiety levels $(p<0.01)$ followed by groups II and III.

Conclusion: Verbal information generated less anxiety than visual information on patients undergoing DI therapy.

Clinical significance: To assess the best method of information delivery to dental implant patients in which their anxiety will be minimal.

Keywords: Anxiety, Dental implant, Verbal information, Visual information.

The Journal of Contemporary Dental Practice (2020): 10.5005/jp-journals-10024-2842
\end{abstract}

\section{INTRODUCTION}

Dental implant (DI) treatment generated a paradigm shift in the rehabilitation process. They used to restore the lost teeth and orofacial defects. ${ }^{1}$ Implant dentistry has undergone progressive development in recent years. The DIs provide better oral hygiene and prevent recurrent caries compared to any other rehabilitation techniques. Patient acceptability and satisfaction rates are also higher with implant therapy as it provides convenience and natural feeling rather than traditional dental treatment procedures. ${ }^{2,3}$

Despite being a popular choice of dental treatment in terms of clinical performance, it is not advised to commence the treatment procedure without considering various treatment aspects. The crucial factor involved in the success of DI treatment is the patient's cooperation during the procedure. As a matter of fact, many patients were found to be anxious about dental treatments, especially with respect to implant treatment. ${ }^{4}$ Anxiety is an emotional response of unformulated uneasiness and reaction to an unknown danger. The cause of distress is associated with the individual's nature and the encircling environment. This unknown fear might be acquired from other individuals, previous unpleasant dental experiences, or an unfavorable environment. Implant-associated anxiety was often due to the fear of surgical procedures and pain involved during or after treatment. ${ }^{4-6}$ If anxiety exists, one is more perceptive to painfulness. Apart from this, individuals are also concerned about the duration of treatment, the length of healing time, cost involved in the treatment, and more importantly the success rate. All these dreadful factors sometimes act as a barrier to implant treatment. ${ }^{6}$ Therefore, alleviating anxiety is one of the essential factors to be considered during treatment plan. Several methods were employed to understand the level of anxiety in dental patients. The modified Corah dental anxiety scale (MDAS), visual analog scale, and dental fear survey are some of the commonly
Division of Prosthodontics, Department of Prosthetic Dental Sciences, College of Dentistry, Jouf University, Sakaka, Kingdom of Saudi Arabia

Corresponding Author: Mohammed Ghazi Sghaireen, Division of Prosthodontics, Department of Prosthetic Dental Sciences, College of Dentistry, Jouf University, Sakaka, Kingdom of Saudi Arabia, Phone: +966 506447244, e-mail: dr.mohammed.sghaireen@jodent.org

How to cite this article: Sghaireen MG. Effect of Verbal and Visual Information on the Level of Anxiety among Dental Implant Patients. J Contemp Dent Pract 2020;21(8):846-851.

Source of support: Nil

Conflict of interest: None

employed anxiety measurement techniques. These methods are not ideal and may not give accurate results always. However, anxiety can be managed based on the results of these techniques, patient's medical condition, and operative needs. Various anxiety management methods such as verbal and audiovisuals information delivery, cognitive behavioral therapy, hypnosis, local, and general anesthesia can be applied based on the level of anxiety. ${ }^{7}$ CamachoAlonso et al. in their study concluded that face-to-face verbal information generates less anxiety than audiovisual information. ${ }^{8}$ Kazancioglu et al. also concluded that media information before DIs increases the level of anxiety. Therefore, face-to-face verbal information is preferred to lessen the anxiety toward DIs. ${ }^{8,9}$

Implant treatment involves a surgical phase that requires local anesthesia. Majority of the patients are anxious about the surgical intervention and further implant treatment processes. Thus, it is advisable to administer appropriate relaxation methods to minimize the anxiety during and after surgical procedures. ${ }^{8}$ Positive feedback is reported for non pharmacological anxiety management methods such as hypnosis and acupuncture technique. Hypnosis with 
relaxation music or text exhibits a significant change in anxious patients. ${ }^{10}$ However, sometimes, these nonpharmacological anxiety management techniques may not be enough for highly anxious patients. Such instances can be effectively managed with inhalation, intravenous (IV) sedation, and general anesthesia. ${ }^{11-16}$ In case of prolonged and challenging DI procedures, patient anxiety level can be managed with advanced sedation technique, which includes IV injection of midazolam followed by propofol infusion or $30 \%$ nitrous oxide inhalation. ${ }^{13}$ Midazolam with fentanyl also exhibits proper sedation. Multiple drugs such as midazolam and butorphanol with continuous infusion of dexmedetomidine or propofol also effective during implant surgical procedures. This combination of drug therapy is limited in dental treatment procedures as it exhibits no beneficial effect over advanced IV sedation technique with midazolam and propofol. ${ }^{15}$ Moreover, excellent communication and rapport between the clinician and patient along with pharmacological approach can provide a satisfactory result during all phases of implant treatment procedures. ${ }^{4-7}$

To the best of our knowledge, no studies are available in the literature, which has compared the effect of videos on manikins, real videos showing the surgical procedure and verbal information on the level of anxiety. So this study was executed to compare the impact of verbal, life surgical videos, and videos on manikins on the level of anxiety in patients undergoing DI therapy. The null hypothesis stated that no difference exists between the verbal and the visual modes of delivering information on the level of anxiety in dental patients undergoing $\mathrm{DI}$ surgery.

\section{Materials and Methods}

This study was conducted at Jouf University Dental Clinics, KSA. The present study was conducted in accordance with the guidelines set by the Helsinki declaration for human researches. Ethical approval was obtained from the human ethical committee at Jouf University (02-05-41). The study was executed during the period of September 2019 and January 2020.

\section{Inclusion and Exclusion Criteria}

Medically fit patients of $>18$ years of age who required DI placement and had no known contraindication for the same were included in the study. Participants who showed their willingness to participate in the study were recruited. Illiterate, medically compromised, or patients who prefer the treatment under general anesthesia and patients with anxious dental history were excluded from the study. Occupational status of the enrolled participants was categorized as medical (includes medical and dental professionals), paramedical (lab technicians and nurses), and others. Two hundred and seventy patients who meet the inclusion criteria participated in this study. Before randomization, the Krantz Health Opinion Survey (KHOS) was filled by all participants and were later analyzed, per the protocol followed by Fabio et al. ${ }^{8}$

Patients were divided and randomly allocated to the three study groups, with 90 patients in each group.

- Group I (conventional verbal information): Information imparted to the patients by an implantologist. The method was standardized by delivering the information that was printed and describing the steps involved in DI treatment.

- Group II (video of surgery on manikins): Patients in this group were allowed to watch a video consisting of installing DI into a dental cast. Similar information was delivered to the participants of this group.
- Group III (video of surgery on real patient): Patients in this group were allowed to watch a video consisting of installing DI into a real patient. The information remained the same for all the groups.

After providing the same information to all patients, the anxiety generated by the three groups was assessed using the MDAS.

\section{Modified Corah Dental Anxiety Scale}

The MDAS is considered as valid, reliable, and easy. ${ }^{17}$ It consists of five questions. Each question has five options ranging from severe anxious ( 5 points) to not anxious at all ( 1 point). An overall score is obtained by adding the individual scores of each question. The interpretation of the overall score was based on the principle where the total score was considered directly proportional to the anxiety level. According to previous studies, patients were considered severely anxious if the sum of the points in the MDAS is higher than 19 , moderately anxious if the sum of the points is between 5 and 10 , and were considered as low anxiety if the sum of the points is between 11 and $18 . .^{3,18,19}$ Data obtained were analyzed using the SPSS software (SPSS 21.0 IBM, and Chicago, IL, USA).

\section{Results}

A total of 270 patients (males 135 and females 135) completed the KHOS and MDAS. The age-group of the patients ranged from 22 to 75 years, with a mean age of $45.66 \pm 12.14$ years. The KHOS scale was analyzed, and the Cronbach's a scores were 0.89 and 0.91. Mean anxiety level values from responses of MDAS were significantly $(p<0.05)$ higher for females in comparison with males (Fig. 1 and Table 1). Post hoc groupwise comparison revealed statistically significant difference $(p<0.05)$ between groups I, II, and III (Table 2$)$. Mean anxiety level values were statistically insignificant $(p>0.05)$ with respect to the occupation (Fig. 2). The occupation was found to be independent in relation to anxiety levels. Mean anxiety level values were highest for group III in comparison with groups II and I, with respect to all responses (Fig. 3). Among group I, only 3.3\% scored above 19 (severe anxiety), while it was $12.2 \%$ and $23.2 \%$ for groups II and III, respectively (Table 3).

\section{Discussion}

An understanding of the origin of dental anxiety is considered as a core issue in its management. A substantial amount of available literature has reported various causative or predisposing factors responsible for dental anxiety. Carter et al. and Sghaireen et al. documented that audiovisual information, cognitive, informative, and parental are the commonest among them. ${ }^{20,21}$ Shoben et al. found that dental anxiety is an acquired feeling rather than connate. ${ }^{22}$

Pommer et al. and AL-Dwairi et al. proposed that it is crucial for the patients receiving DIs to be informed about the procedure as it can be a causative factor for dental anxiety. ${ }^{23,24}$ The DI patients usually obtain their initial information from their friends, acquaintances, relatives, or social media. $8,25,26$

In this study, KHOS was used to assess sample homogeneity. This survey consists of two subscales that, in general, measured the homogeneity of the sample. The values of Cronbach's a and the behavioral involvement subscale were 0.89 and 0.91 , respectively, indicating a hemogeneous sample. ${ }^{8,27}$ To measure the level of anxiety, MDAS $^{18}$ was used in the current study. It is a validated and frequently used tool to measure the dental anxiety. ${ }^{17}$ There 


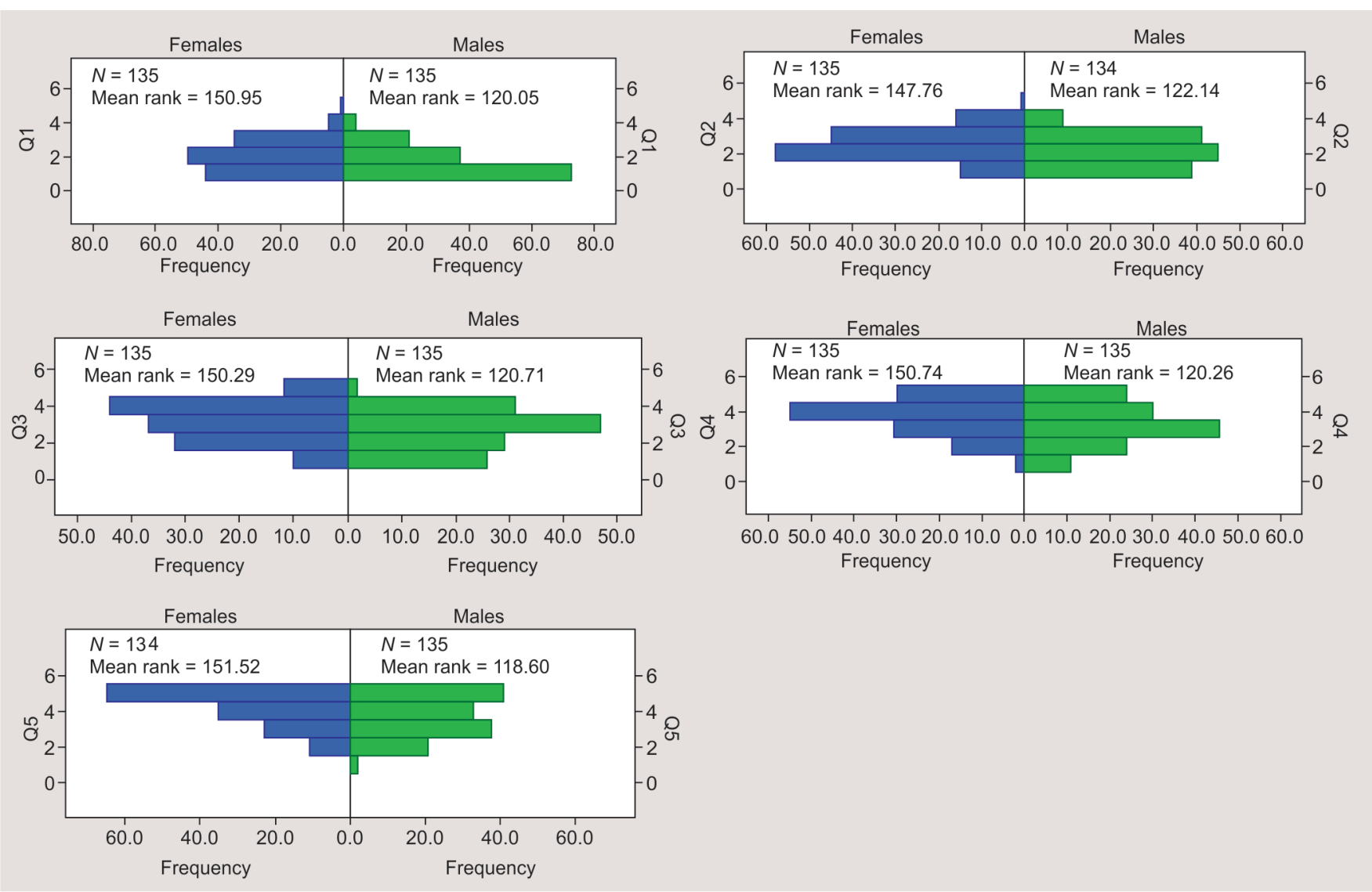

Fig. 1: Mean anxiety level values from responses of modified Corah dental anxiety scale among males and females

Table 1: Gender comparison for responses with in groups I, II, and III based on the modified corah dental anxiety scale

\begin{tabular}{llll}
\hline Responses comparison in males vs females & & \\
\hline Modified Corah dental anxiety scale & Mann-Whitney U & Standard error & p value \\
\hline $\begin{array}{l}\text { Q1. If you are going to visit the dental implantologist, how would you } \\
\text { describe your feeling? }\end{array}$ & $11,198.5$ & 600.5 & 0.001 \\
$\begin{array}{l}\text { Q2. When you are sitting in the waiting room at the implantologist clinic, } \\
\text { how would you describe your feeling? }\end{array}$ & 10,768 & 606 & 0.004 \\
$\begin{array}{l}\text { Q3. When you are sitting in the dental chair and the implantologist is } \\
\text { preparing his/her instrument, how would you describe your feeling? }\end{array}$ & $11,108.5$ & 620.1 & 0.001 \\
$\begin{array}{l}\text { Q4. When you are sitting in the dental chair and you are about to get } \\
\text { injected with local anesthesia, how would you describe your feeling? }\end{array}$ & 11,170 & 620 & 0.001 \\
$\begin{array}{l}\text { Q5. When the implantologist start the surgery, how would you describe } \\
\text { your feeling? }\end{array}$ & 11,258 & 608.3 & 0.000 \\
\hline
\end{tabular}

is no question regarding anesthesia in the original scale, thus, the modified version was used. Kleinknecht, in his study, found that a dentist's needle is one of the most essential factors that result in fear among the dental patients. ${ }^{28}$

In this study, half of the recruited patients were female ( $n=135)$ and the level of anxiety among female was significantly higher than male $(p<0.05)$ (Fig. 1 and Table 1). This could be explained by the fact that women are more passionate than men. ${ }^{29}$ Moreover, men usually try not to express their fear openly compared to female. ${ }^{30}$ These findings are congruent with the studies that showed anxiety to be higher among females..$^{21,31}$ On the contrary, some other studies found that there is no difference between the genders which contradicts the finding of the current study. ${ }^{27,32-34}$
These differences between researchers may be due to cultural or educational background.

In relation to occupation, it was found that there were no differences in anxiety level among the different occupations $(p>0.05)$ (Fig. 2). This result corroborated with the observations made in the previous studies. ${ }^{35,36}$ However, Mulholland et al. concluded that anxiety is lower in patients with jobs, regardless of their occupation type. A plausible explanation for the finding of the current study could be the interaction of various factors such as age, gender, level of education, and race. Further studies are needed to explore the current results.

In relation to the method of information delivering, it was found that level of the anxiety was the least among group I (conventional 
Table 2: Post hoc comparison of groups I, II, and III for responses of Corah dental anxiety scale

\begin{tabular}{|c|c|c|c|c|}
\hline Questionnaire of modified Corah dental anxiety scale & Group comparison & Test statistics & Standard error & $p$ value \\
\hline \multirow{3}{*}{$\begin{array}{l}\text { Q1. If you are going to visit the dental implantologist, how } \\
\text { would you describe your feeling? }\end{array}$} & Group I vs group II & -52.85 & 10.89 & 0.000 \\
\hline & Group I vs group III & -83.12 & & 0.000 \\
\hline & Group II vs group III & -30.12 & & 0.000 \\
\hline \multirow{3}{*}{$\begin{array}{l}\text { Q2. When you are sitting in the waiting room at the implan- } \\
\text { tologist clinic, how would you describe your feeling? }\end{array}$} & Group I vs group II & -55.51 & 11.04 & 0.000 \\
\hline & Group I vs group III & -101.87 & & 0.000 \\
\hline & Group II vs group III & -46.28 & & 0.000 \\
\hline \multirow{3}{*}{$\begin{array}{l}\text { Q3. When you are sitting in the dental chair and the implan- } \\
\text { tologist is preparing his or her instrument, how would } \\
\text { you describe your feeling? }\end{array}$} & Group I vs group II & -67.57 & 11.25 & 0.000 \\
\hline & Group I vs group III & -118.75 & & 0.000 \\
\hline & Group II vs group III & -51.17 & & 0.000 \\
\hline \multirow{3}{*}{$\begin{array}{l}\text { Q4. When you are sitting in the dental chair and you are } \\
\text { about to get injected with local anesthesia, how would } \\
\text { you describe your feeling? }\end{array}$} & Group I vs group II & -63.83 & 11.25 & 0.000 \\
\hline & Group I vs group III & -118.63 & & 0.000 \\
\hline & Group II vs group III & -54.8 & & 0.000 \\
\hline \multirow{3}{*}{$\begin{array}{l}\text { Q5. When the implantologist starts the surgery, how would } \\
\text { you describe your feelings? }\end{array}$} & Group I vs group II & -78.31 & 11.15 & 0.000 \\
\hline & Group I vs group III & -124.50 & & 0.000 \\
\hline & Group II vs group III & -46.01 & & 0.000 \\
\hline
\end{tabular}
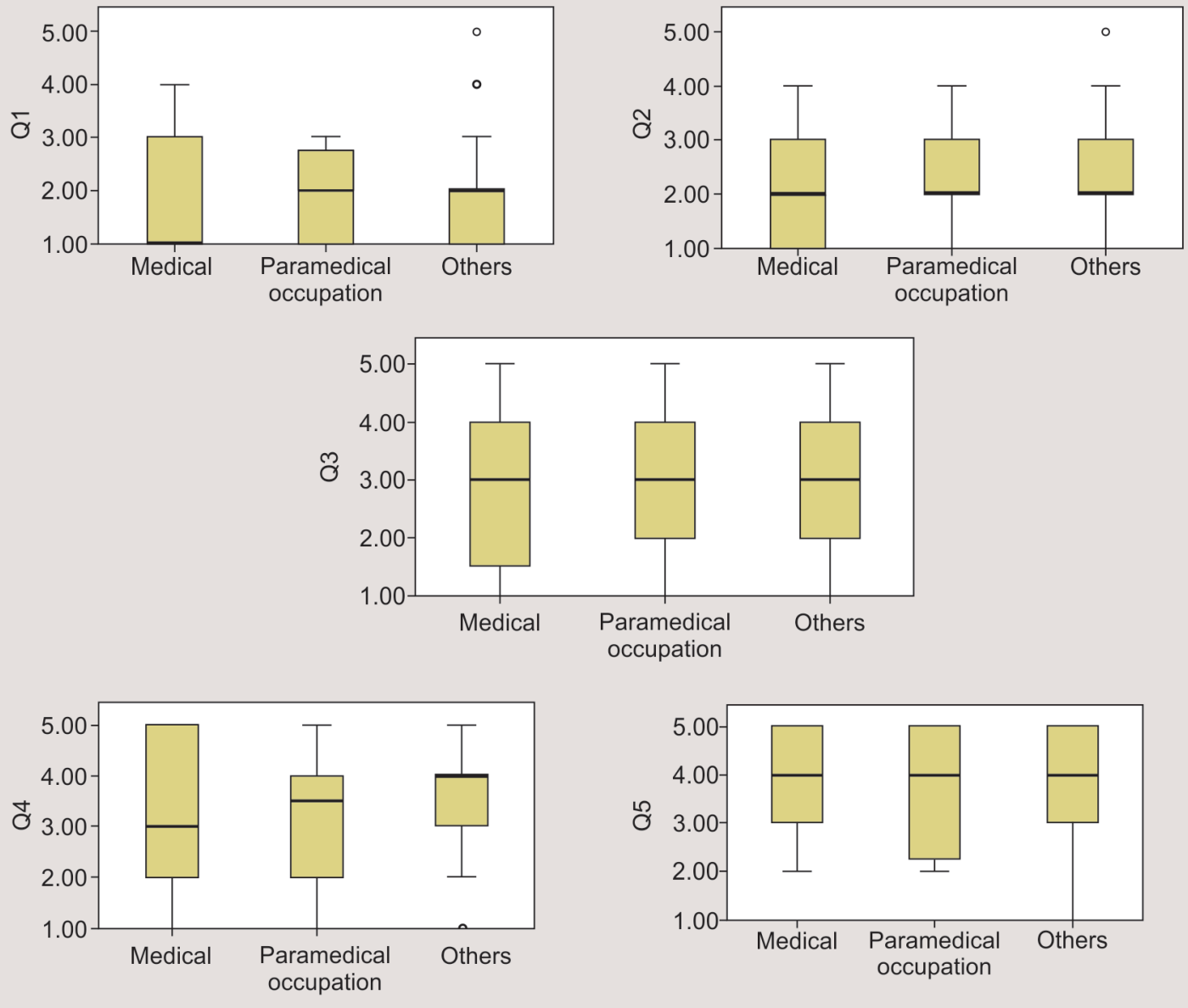

Fig. 2: Mean anxiety level with respect to the occupation of the patients 


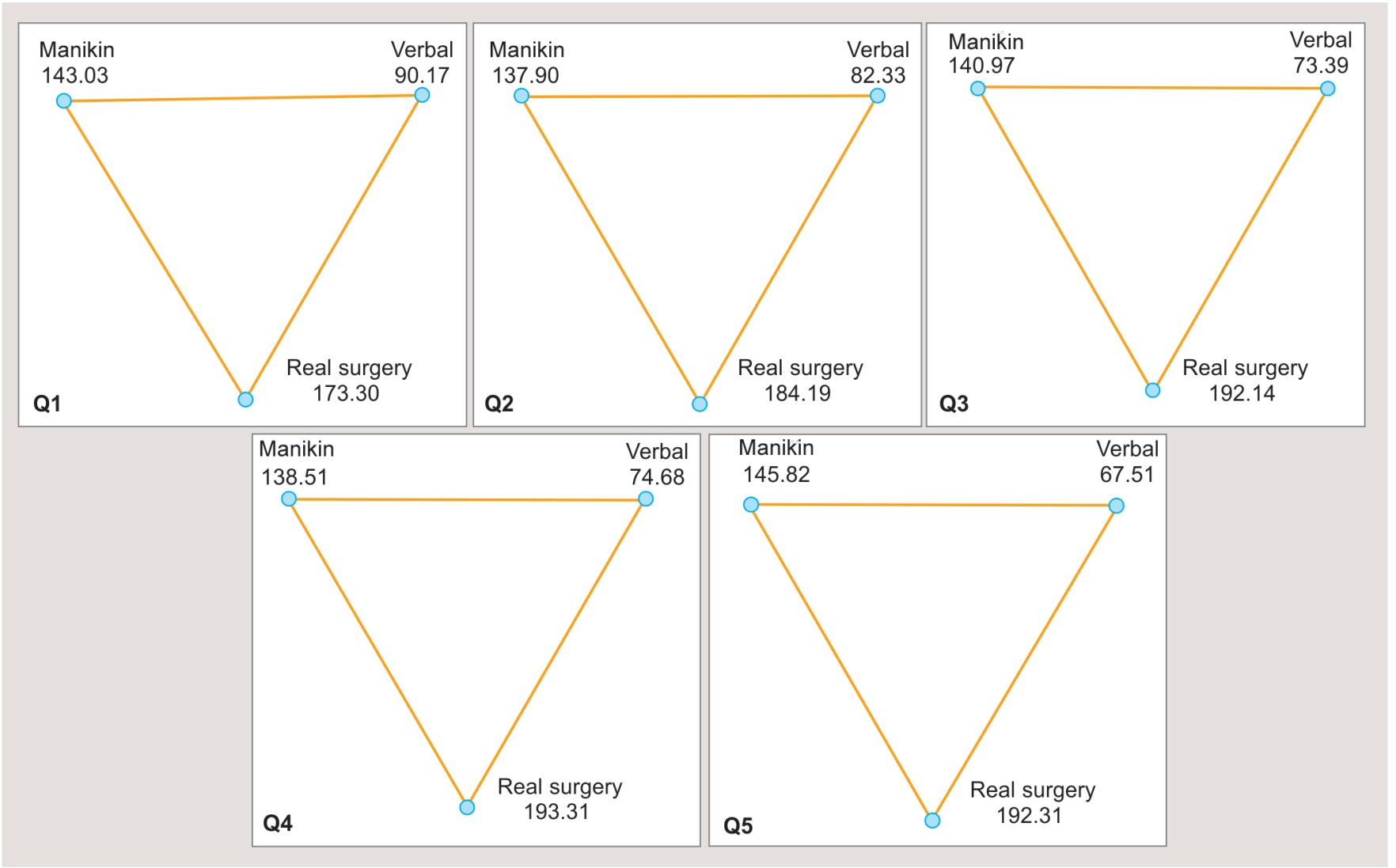

Fig. 3: Mean of anxiety level among the three groups

Table 3: Comparative analysis of anxiety scores among the groups

\begin{tabular}{llrrc}
\hline Groups & $\begin{array}{l}\text { Anxiety score } \\
\text { scaled }\end{array}$ & Frequency & Percent & $\begin{array}{l}\text { Cumulative } \\
\text { percent }\end{array}$ \\
\hline Group I & $=>19.00$ & 87 & 96.7 & 3.3 \\
& $20.00-21.00$ & 3 & 3.3 & 100.0 \\
& Total & 90 & 100.0 & \\
Group II & $=>19.00$ & 79 & 87.8 & 12.2 \\
& $20.00-21.00$ & 10 & 11.1 & 98.9 \\
& $22.00+$ & 1 & 1.1 & 100.0 \\
& Total & 90 & 100.0 & \\
Group III & $=>19.00$ & 69 & 76.7 & 26.3 \\
& $20.00-21.00$ & 16 & 17.8 & 94.4 \\
& $22.00+$ & 5 & 5.6 & 100.0 \\
& Total & 90 & 100.0 & \\
\hline
\end{tabular}

verbal information) $(p<0.05)$ followed by group II (video of surgery on manikins) and group III (video of surgery on real patients), respectively (Table 3 and Fig. 3). The possible explanation for these finding is that some patients may feel uneasy about the scene of the needle and blood. In addition to that cutting, the tissue with the blade might increase the level of anxiety. Moreover, drilling the bone, implant screwing, and suturing might have a serious impact on the level of the patient's fear and anxiety. These results concur with a study conducted by Fabio et al. who used audiovisual method in their study, and the characteristics inherent to audiovisual language might affect their findings. ${ }^{8}$ Other studies have found that audiovisual information can elevate patients' anxiety. ${ }^{37}$

Videography on manikins was expected to be effective in lowering the level of anxiety compared to the conventional verbal imparting. In this study, it was found that conventional verbal imparting showed the least anxiety level. This might be due to the scene of cutting, drilling, and suturing. It seems that when the patients have an opportunity to discuss issues of concern with surgeon and staff surprisingly, the level of anxiety decreases. Surprisingly, visual and audiovisual showed good results in general surgery but not in dentistry. This might be explained by the fact that dental procedures generally generate sounds, vibration, water irrigation, and also happens very close to the patients' eyes.

Although it is unclear in the literature and the researches conducted to compare which model of information delivery is most cost-effective, least anxious, most patients indicated that they would like to receive enough information about their surgeries. ${ }^{38}$ Misunderstandings that might result from audiovisual delivering system can only be clarified by giving patients the opportunity to discuss their cases with the dentist or the staff members.

Further research are needed with greater sample size and different ways of information delivery such as pamphlet, leaflet, video, meeting with play specialist, and group information sessions. The DI is an important public health concern, and its prevalence has increased in the last 20 years, its avoidance as a result of anxiety might affect the general health of patients and affects their quality of life. Considering the sample size, and as the results depend on questionnaires, further clinical studies must use standardized procedures.

\section{Conclusion}

In conclusion, direct verbal information generates fewer levels of anxiety in contrast to the visual information in the patient who was about to receive a DI. Female showed a higher level of anxiety, 
whereas the type of employment of the patients did not show an effect on the level of anxiety.

\section{ACKnOWLedgment}

Thanks to Dr Hussien Al-Shareef who produced and edited the videos.

\section{References}

1. Rizwan $\mathrm{H}$, Kaleem M, Zahid S, et al. Potential of dental implants as drug carriers. Pakistan Oral Dent J 2017;37(4):561-565.

2. Sghaireen MG, Al-Omiri MK. Relationship between impact of maxillary anterior fixed prosthodontic rehabilitation on daily living, satisfaction, and personality profiles. J Prosthet Dent 2016;115(2): 170-176. DOI: 10.1016/j.prosdent.2015.07.009.

3. Jivraj S, Chee W. Rationale for dental implants. Br Dent J 2006;200(12):661. DOI: 10.1038/sj.bdj.4813718.

4. Prathima V, Anjum MS, Reddy PP, et al. Assessment of anxiety related to dental treatments among patients attending dental clinics and hospitals in Ranga Reddy district, Andhra Pradesh, India. Oral Health Prev Dent 2014;12(4):357-364. DOI: 10.3290/j.ohpd.a31660.

5. Candido MC, Andreatini R, Zielak JC, et al. Assessment of anxiety in patients who undergo surgical procedures for tooth implants: a prospective study. Oral Maxillofac Surg 2015;19(3):253-258. DOI: 10.1007/s10006-014-0480-3.

6. Hashem AA, Claffey NM, O'Connell B. Pain and anxiety following the placement of dental implants. Int J Oral Maxillofac Implan 2006;21(6):943-950.

7. Astramskaite I, Pinchasov G, Gervickas A, et al. Validation of universal scale in oral surgery (USOS) for patient's psycho-emotional status rating. J Oral Maxillofac Res 2017;8(4):e2. DOI: 10.5037/jomr.2017.8402.

8. Camacho-Alonso F, Vilaplana-Vivo J, Caballero-Guerrero PM, et al. Impact of audiovisual information on anxiety and fear in patients undergoing dental implant treatment. Clin Implant Dent Relat Res 2019;21(6):1189-1198. DOI: 10.1111/cid.12851.

9. Kazancioglu H-O, Dahhan A-S, Acar A-H. How could multimedia information about dental implant surgery effects patients' anxiety level? Med Oral Patol Oral Cir Bucal 2017;22(1):e102. DOI: 10.4317/ medoral.21254.

10. Vachiramon A, Wang WC, Vachiramon T. The use of acupuncture in implant dentistry. Implant Dent 2004;13(1):58-64. DOI: 10.1097/01. id.0000116453.02519.c1.

11. Taguchi T, Fukuda $\mathrm{K}$, Sekine $\mathrm{H}$, et al. Intravenous sedation and hemodynamic changes during dental implant surgery. Int J Oral Maxillofac Implan 2011;26(6):1303-1308.

12. Stamp AJ, Dorman ML, Vernazza CR, et al. Can intravenous conscious sedation with midazolam be effective at facilitating surgical dentistry in adolescent orthodontic patients? A service evaluation. Br Dent J 2017;222(2):113. DOI: 10.1038/sj.bdj.2017.78.

13. Yamamoto $\mathrm{T}$, Fujii-Abe $\mathrm{K}$, Fukayama $\mathrm{H}$, et al. The effect of adding midazolam to propofol intravenous sedation to suppress gag reflex during dental treatment. Anesth Prog 2018;65(2):76-81. DOI: 10.2344/ anpr-65-02-03.

14. Tobias JD, Leder M. Procedural sedation: a review of sedative agents, monitoring, and management of complications. Saudi J Anaesth 2011;5(4):395-410. DOI: 10.4103/1658-354X.87270.

15. Wakita R, Kohase H, Fukayama H. A comparison of dexmedetomidine sedation with and without midazolam for dental implant surgery. Anesth Prog 2012;59(2):62-68. DOI: 10.2344/11-11.1.

16. CARE PO. Practice guidelines for intravenous conscious sedation in dentistry (2017). Anesth Prog 2018;65(4):e1-e18. DOI: 10.2344/anpr65-04-15w.

17. Corah NL, Gale EN, Illig SJ. Assessment of a dental anxiety scale. J Am Dent Associat (1939) 1978;97(5):816-819. DOI: 10.14219/jada. archive.1978.0394.

18. Humphris GM, Morrison T, Lindsay S. The modified dental anxiety scale: validation and United Kingdom norms. Commun Dent Health 1995.
19. Coolidge T, Chambers MA, Garcia LJ, et al. Psychometric properties of spanish-language adult dental fear measures. BMC Oral Health 2008;8(1):15. DOI: 10.1186/1472-6831-8-15.

20. Carter AE, Carter G, Boschen M, et al. Pathways of fear and anxiety in dentistry: a review. World J Clin Cases 2014;2(11):642-653. DOI: 10.12998/wjcc.v2.i11.642.

21. Sghaireen MG, Zwiri AMA, Alzoubi IA, et al. Anxiety due to dental treatment and procedures among university students and its correlation with their gender and field of study. Int J Dent 2013;2013:647436. DOI: 10.1155/2013/647436.

22. Shoben JrEJ, Borland L. An empirical study of the etiology of dental fears. J Clin Psychol 1954;10(2):171-174. DOI: 10.1002/10974679(195404)10:23.0.co;2-o.

23. Pommer B, Zechner W, Watzak G, et al. Progress and trends in patients' mindset on dental implants. I: level of information, sources of information and need for patient information. Clin Oral Implants Res 2011;22(2):223-229. DOI: 10.1111/j.1600-0501.2010.02035.x.

24. AL-Dwairi ZN, El Masoud BM, Al-Afifi SA, et al. Awareness, attitude, and expectations toward dental implants among removable prostheses wearers. J Prosthodont 2014;23(3):192-197. DOI: 10.1111/jopr.12095.

25. Sghaireen MG, Al-Zarea BK, Al-Shorman HM, et al. Clinical measurement of the height of the interproximal contact area in maxillary anterior teeth. Int J Health Sci 2013;7(3):325. DOI: 10.12816/0006061.

26. Mousa MA, Lynch E, Sghaireen MG, et al. Influence of time and different tooth widths on masticatory efficiency and muscular activity in bilateral free-end saddles. Int Dent J 2017;67(1):29-37. DOI: 10.1111/ idj.12256.

27. Sghaireen MG, Al-Omiri M, Patil S, et al. Maximum bite force for children on primary and permanent teeth: within subject comparison. Europ Sci J 2014;10(30):1857-7881.

28. Kleinknecht RA, Klepac RK, Alexander LD. Origins and characteristics of fear of dentistry. J Am Dent Associat 1973;86(4):842-848. DOI: 10.14219/jada.archive.1973.0165.

29. Bergdahl M, Bergdahl J. Temperament and character personality dimensions in patients with dental anxiety. Eur J Oral Sci 2003;111(2):93-98. DOI: 10.1034/j.1600-0722.2003.00028.x.

30. Anzar W, Afaq A, Baig QA. Assessment of dental anxiety in adults undergoing dental procedures in Dow international dental college. J Dow Univer Health Sci (JDUHS) 2017;11(1).

31. Acharya S, Sangam DK. Dental anxiety and its relationship with selfperceived health locus of control among Indian dental students. Oral Health Prev Dent 2010;8(1):9-14.

32. Berggren U, Carlsson SG. Psychometric measures of dental fear. Commun Dent Oral Epidemiol 1984;12(5):319-324. DOI: 10.1111/ j.1600-0528.1984.tb01463.x.

33. Economou GC. Dental anxiety and personality: investigating the relationship between dental anxiety and self-consciousness. J Dent Educ 2003;67(9):970-980.

34. Thomson WM, Locker D, Poulton R. Incidence of dental anxiety in young adults in relation to dental treatment experience. Commu Dent Oral Epide 2000;28(4):289-294. DOI: 10.1034/j.16000528.2000.280407.x.

35. Mulholland F, Jackson J. The experience of older adults with anxiety and depression living in the community: aging, occupation and mental wellbeing. Br J Occupat Ther 2018;81(11):657-666. DOI: 10.1177/0308022618777200.

36. Patel PA, Patel PP, Khadilkar AV, et al. Impact of occupation on stress and anxiety among Indian women. Women Health 2017;57(3):392401. DOI: 10.1080/03630242.2016.1164273.

37. Salzwedel C, Petersen C, Blanc I, et al. The effect of detailed, videoassisted anesthesia risk education on patient anxiety and the duration of the preanesthetic interview: a randomized controlled trial. Anesthe Analges 2008;106(1):202-209. DOI: 10.1213/01. ane.0000287665.96156.72.

38. Stewart A, Sodhi V, Harper N, et al. Assessment of the effect upon maternal knowledge of an information leaflet about pain relief in labour. Anaesthesia 2003;58(10):1015-1019. DOI: 10.1046/j.13652044.2003.03360.x. 